anaemia, eosinophilia, and retardation of growth. ${ }^{10}$ This new syndrome has been delineated on the basis of clinical features, gastrointestinal radiography, intestinal biopsies, and favourable response to corticosteroid therapy. The last distinguishes it in this age group particularly from intestinal lymphangiectasia, coeliac disease, and hypogammaglobulinaemia. T. A. Waldman and colleagues ${ }^{10}$ propose the term allergic gastroenteropathy to delineate their series of cases because milk aggravated the protein-losing gastroenteropathy. Precipitating antibodies to milk were detected in the serum of three patients. The patients improved on a milk-free diet and relapsed when milk was reintroduced. The favourable response to the administration of corticosteroids, together with clinical signs of asthma, eczema, and rhinitis, all contributed to the concept of an allergic gastroenteropathy.

This series of six children comprised four boys and two girls. The age at onset of oedema was under 3 years in all but one child. Oedema was most marked in the periorbital area. Gastrointestinal symptoms included diarrhoea and vomiting after milk; but lactose tolerance tests were normal. Gastrointestinal $x$-ray examinations showed mucosal oedema of the small bowel in four and puddling and segmentation of barium in one patient. The authors are confident that this distinctive syndrome is not attributable to any of the previously recognized conditions that give rise to excessive loss of protein into the gastrointestinal tract, and that a trial of treatment with a milk-free diet or with corticosteroids is worth while.

Hitherto the clinical patterns of disease associated with loss of protein have been classified according to whether the lesion is outside or inside the gastrointestinal tract: in the heart, liver, or pancreas, or in the stomach, small intestine, or the colon. We must now also keep in mind gastrointestinal allergens, whether food or drug, which may contribute in turn to this gastrointestinal upset, metabolic disorder, and systemic disease, for early recognition is the first step away from the label "idiopathic oedema" and towards a rational basis of treatment.

Correction of protein-losing gastroenteropathy has followed surgical treatment of constrictive pericarditis and other cardiac abnormalities. ${ }^{7}$ Gastrectomy for giant hypertrophy of the gastric rugáe has effected a cure, and so has putting gluten-allergic patients on a gluten-free diet. Corticosteroid therapy has proved beneficial in ulcerative colitis, and now also for milk-allergy protein-losing gastroenteropathy.

\section{Oxygen Therapy Equipment}

Oxygen is usually given in low dosage ( $25 \%$ to $40 \%$ ) for treatment of hypoxaemia due to uneven lung function. In particular it may be given for under-ventilation or overperfusion of groups of alveoli. The patient is usually suffering from lung disease ${ }^{1}$ or has a disturbance of the pulmonary circulation, as in some cases of myocardial infarction. ${ }^{2}$ Oxygen is given in high dosage ( $70 \%$ to $100 \%$ ) both to produce a high tension in the blood, as for treatment of carbon monoxide poisoning, and to increase the quantity of oxygen carried in solution in blood plasma. The latter procedure may contribute to the relief of tissue hypoxia due to ischaemia and of hypoxaemia due to blood by-passing ventilated regions of lung. Both these conditions arise in patients with severe myocardial infarction. ${ }^{3}$

A high dosage of oxygen in a patient whose breathing is not depressed may be secured with a half face mask which makes a good fit on to the face and is supplied with a generuus flow of oxygen $(6-10 \mathrm{l} / \mathrm{min}$.). The effectiveness of the oxygen is enhanced by using a mask with a reservoir bag for conserving the gas which would otherwise flow to waste during expiration-for example, the Portogen mask. Use of a mask which falls from the face on interruption of the oxygen supply-for example, the Pneumask-has some advantage, but is not essential, because with adequate respiration the interruption is unlikely to give rise to asphyxia. If breathing may become depressed a more positive means of administration is desirable.

Oxygen in low dosage is easily provided and does not require a perfectly fitting mask. As only a low flow is required there is no need for conservation of oxygen during expiration except when portable equipment is used. The risk of asphyxia is small for patients who are hyperventilating-for example, those with a defect of gas transfer in the lungs or in a state of shock. But this type of therapy is usually needed for patients whose ventilation is low, perhaps owing to an acute chest iliness superimposed on chronic lung disease or to depression of the respiratory centre. Here the oxygen should relieve the hypoxaemia sufficiently to prevent tissue damage, but preferably without eliminating the hypoxic drive to respiration. An arterial oxygen saturation of $90 \%$ is suitable for this purpose. The gas should be administered in controlled dosage and, when appropriate, with monitoring of the blood carbon-dioxide tension and $\mathrm{pH}$. This is to prevent hypoventilation leading to carbon dioxide narcosis owing to reduction of the stimulus to breathing. For these patients the device should have minimal deadspace to avoid aggravation of the carbon dioxide retention. The dead-spaces of equipment in current use have recently been investigated."

Plastic nasal catheters meet the requirement, are comfortable, and can be used during meals, but the oxygen then requires humidification, and for a few patients mouth breathing may lower the effective dose. The Ventimask is also satisfactory and has the advantage that the concentration of oxygen is nearly constant. ${ }^{5}$ However, up to three face pieces may $b$ c needed per patient if a range of concentrations is requires $24 \%-35 \%$ ). Of the others which do not conserve oxygen during expiration, the M.C. mask was found to have a significant dead-space ${ }^{6}$ and so to be inferior to the Edinburgh mask, in which there is free communication with the outside air. ${ }^{7}$ The latter mask is probably the best single one for general use.

Masks which have a large dead-space include the Polymask, Pneumask, and those of the B.L.B. type. Because of the hazard of rebreathing these should never be used for patients who are liable to carbon dioxide narcosis. In addition, while the masks can provide high enrichment of oxygen for patients needing $100 \%$ oxygen, they are inferior in this respect to masks like the Portogen, mentioned above, in which rebreathing is prevented by use of valves. ${ }^{8}$

Modern oxygen therapy requires separate devices for administering oxygen in high and low doses. The physician

\footnotetext{
1 Campbell, E. J. M., Lancet, 1960, 2, 10.

Valentine, P. A., Fluck, D. C., Mounsey, J. P. D., Reid, D., Shilling-

ford, J. P., and Steiner, R. E., ibid., 1966, 2, 837 .

MacKenzie, G. J., Taylor, S. H., Flenley, D. C., McDonald
Staunton, H. P., and Donald, K. W., ibid., 1964, 2, 825 .

- Bethune, D. W., and Collis, J. M., Thorax, 1967, 22, 221 .

- Bethune, D. W., and Collis, J. M., Thorax, 1967, 22, 221.

- Campell, E. J. M., and Gebbie, T., Lancet, 1966, 1, 468. $1,415$.

- Catterall, M., Kazantzis, G., and Hodges, M., ibid., 1967, 1, 415. 1963, 2, 1081 .

Cotes, J. E., and Merrick, A. J., ibid., 1956, 1, 269.
} 
is now in a position to select the most suitable one for each purpose from the equipment commercially available.

\section{Children in Care}

Until about 1960 the annual numbers of illegitimate births and of marriages ending in divorce in England and Wales had not shown a distinct trend up or down since the peak years immediately after the second world war. Then in 1961 the rates for both rose sharply, and they have continued to do so. In $1965^{1}$ the number of illegitimate babies born was 66,249 , or 77 per 1,000 total live births, and the number of divorces was 37,785 , or 3.1 per 1,000 married population. Since in many cases the welfare of young children is affected, it is no surprise to learn from the latest report of the Children's Department of the Home Office ${ }^{2}$ that between 1959 and 1966 the total number of children in the care of local authorities and voluntarv organizations in England and Wales rose from 78,648 t. 79,995. But some comfort may be taken from the fact that the increase was not greater, for it actually represents a fall from 6.5 to 6.1 per 1,000 of the population aged under 18 .

Illness of a parent and confinement of the mother together provide the main immediate cause of children coming into the care of local authorities; the second largest cause of being taken into care is desertion by the mother. The increase in the latter type of cases from 1963 to 1966 was $31 \%$. More remarkable perhaps is the increase of $81 \%$ (from 1,319 to 2,283 ) in the same period of children taken into the care of local authorities owing to unsatisfactory home conditions. The continual improvement in housing for some years might have suggested that a diminution in this category would have been more probable than such a substantial increase.

Since it is now generally acknowledged that a child is better brought up in a family than in an institutional home, however kindly and carefully run, it is worth noting that children's departments are placing many more children with foster parents than formerly and that the numbers of legal adoptions continue to rise each ycar. Between 1959 and 1965 the number of children adopted annually rose by $50 \%$ from 14,000 to 21,000 . Of the latter total $80 \%$ were illegitimate. In view of the important contribution that adoption is now making to the well-being of a considerable fraction of the population the special problems it poses deserve careful study. This is equally true of the individual case, in which a medical man may be called upon to give an opinion in a variety of circumstances. The pitfalls in trying to assess the future health of very young babies are well known, and they are more numerous than usual when one or both parents are inaccessible, as is a feature of many adoption cases. Some of the special problems have been discussed by J. A. Black and F. H. Stone. ${ }^{3}$ But a doctor's role may extend far beyond an assessment of the child's health and thrust upon him legal as well as medical responsibilities. Of these Hilda Lewis ${ }^{4}$ provided an instructive account.

As the report says, "Far too little is known about what makes for a successful adoption, or indeed about how one

\footnotetext{
1 The Registrar General's Statistical Review of England and Wales for the Year 1965, Pt. 2, Tables, Population, 1967. H.M.S.O.

2 Report on the Work of the Children's Department 1964-1966, Home Office, 1967. H.M.S.O.

- Black, J. A., and Stone, F. H., Lancet, 1958, 2, 1272.

- Lewis, H. N., Brit. med. F., 1965, 2, 577.
}

should measure "success." It might perhaps have said the same of parenthood. However that may be, society must accept a special responsibility to ensure that the adoptive procedures it sanctions are as beneficial as possible. Consequently, the studies of its efficacy sponsored by the Home Office, and briefly mentioned in the report, are to be welcomed.

\section{Sentence Without Trial}

A letter in our correspondence columns (p. 556) draws attention to the case of Dr. Raymond Hoffenberg, senior lecturer in the Department of Medicine at Cape Town University, on whom the South African Department of Justice has recently served a banning order. Professor John F. Brock, head of the department in which Dr. Hoffenberg works and President of the College of Physicians, Surgeons, and Gynaecologists of South Africa, has already strongly condemned the action of the Department of Justice. ${ }^{1}$

Dr. Hoffenberg is a distinguished physician, medical scientist, and teacher at Groote Schuur Hospital, Cape Town, known and consulted internationally for his work on radioisotopes, thyroid function, and protein malnutrition. He was formerly acting chairman of the banned South African Defence and Aid Fund, a body which helped political prisoners. ${ }^{2}$ Two years ago his passport was withdrawn. No charges were made against him, and inquiries by Professor Brock failed to elicit the reason for the withdrawal. Nor recently could he obtain permission for Dr. Hoffenberg to attend, on behalf of his hospital and university, an international atomic energy meeting in Vienna to which he had been invited. Now a five-year banning order has been imposed, again without any charges being made. The ban ${ }^{3}$ restricts Dr. Hoffenberg to the Cape Town area, requires him to report weekly to the police, and prevents him from attending any gathering, social or otherwise, of more than one person. $\mathrm{He}$ is forbidden to publish, and this apparently includes scientific articles. He must give up his academic appointment at Groote Schuur Hospital at the end of this year. In the words of correspondents to The Times," "He is removed from the world of medical science, to which he has made notable contributions; he is expunged from society"-all without trial.

Banning orders have been applied to other citizens of South Africa, but not before, it seems, to a medical man. Many South African doctors are shocked by what has occurred, and the College of Physicians, Surgeons, and Gynaecologists, the South African Medical and Dental Council, and the Medical Association of South Africa are to be asked to report on Dr. Hoffenberg's case.

By its actions the Department of Justice has effectively deprived the world of medicine, abroad as well as in South Africa, of the services of a distinguished doctor. No research worker can hope to maintain his impetus without freedom to associate with colleagues, to travel, and to publish his findings. It concerns the profession everywhere that any State, without charge or trial, should thus excommunicate a doctor from his professional life. South Africa will damage only its own reputation if it persists in penalizing Dr. Hoffenberg without a fair hearing.

\footnotetext{
1 Cape Times, 2 August 1967.

2 The Times, 4 August 1967.

- Sunday Times, 6 August 1967.

The Times, 17 August 1967.
} 